\title{
Решения Европейского суда по правам человека и правовая система Российской Федерации
}

Зимненко Б.Л. *

30 марта 1998 года Российская Федерация Федеральным законом «О ратификации Конвенции о защите прав человека и основных свобод и Протоколов к ней» ратифицировала Европейскую конвенцию о защите прав человека и основных свобод от 4 ноября 1950 года с изменениями, внесенными Протоколами к ней №№ $3,5,8$, и дополнениями, содержащимися в Протоколе № 2 , и Протоколы к ней № № 1, 4, 7, 9, 10, 11 (далее «Конвенция»), и с 5 мая 1998 года, с момента передачи ратификационных грамот Генеральному секретарю Совета Европы, указанная выше Конвенция и соответствуюшие Протоколы к ней стали обязательными для Российской Федерации' .

Как известно, одна из особенностей данного международного договора о правах и свободах человека заключается в том, что для обеспечения соблюдения международно-правовых обязательств, принятых на себя Высокими Договаривающимися Сторонами по Конвенции, был учрежден Европейский суд по правам человека (далее - Суд) ${ }^{2}$. В ходе своей деятельности при рассмотрении межгосударственных дел и дел, основанных на индивидуальных жалобах, Суд принимает решения о приемлемости и постановления по существу ${ }^{3}$. В связи с этим не толь-

- Зимненко Богдан Леонидович - к.ю.н., старший преподаватель кафедры международного права Дипломатической академии МИД России, адвокат.

${ }^{\prime}$ В соответствии со статьей 9 Протокола № 7 к Европейской конвенции о защите прав человека и основных свобод указанный Протокол вступил в силу для Российской Федерации I августа 1998 года.

2 К настоящему времени в отечественной литературе деятельность Суда с учетом Протокола № 11 к Конвенции, вступившего в силу с 1 ноября 1998 года, была детально проанализирована, в частности, профессором В.А. Тумановым в его работе: Европейский суд по правам человека. Очерк организации и деятельности, М.: Норма, 2001. ${ }^{3}$ Когда Европейский суд по правам человека принимает судебный акт о приемлемости жалобы, такой судебный акт именуется решением (англ. decision). В случае, когда Судом выносится судебный акт по сушеству, такой судебный акт именуется постановлением (англ. judgment) (ст. 45 Конвенцин). 
ко в теоретическом, но и в практическом плане возникает вопрос: какое место в правовой системе России занимают данные судебные акты, можно ли в настоящее время говорить о том, что решения и постановления Европейского суда по правам человека становятся источником внутригосударственного права России; иными словами, можно ли говорить применительно к деятельности Суда о формировании прецедентного права в Российской Федерации?

Конвенция наделила Европейский суд по правам человека компетенцией не только применять содержащиеся в ней положения, но и осуществлять ее толкование (ст. 32 Конвенции). Таким образом, в рамках Совета Европы, под эгидой которого и была принята Европейская конвенция о защите прав человека и основных свобод, право толковать и применять положения, содержащиеся в Конвенции, принадлежит исключительно Суду.

Как известно, при вынесении решения или постановления практически по каждому делу Суд для обоснования своей позиции ссылается на ранее вынесенные им (Судом) решения и постановления. В связи с тем, что к настоящему времени Европейский суд по правам человека в отношении России рассмотрел по сушеству 8 дел, представляется возможным и необходимым привести некоторые выдержки из данных судебных актов.

К примеру, по делу Бурдов против Российской Федерачии Европейский суд по правам человека, констатировав, что несвоевременное исполнение судебного решения нарушает право на справедливое судебное разбирательство, сослался на постановление Суда от 19 марта 1997 года по делу Hornsby vs. Greece. Отметив, что по смыслу статьи 1 Протокола № 1 к Конвенции требование о взыскании денежных средств, содержашееся в национальном судебном решении, включается в понятие собственности, Европейский суд по правам человека сослался на постановление от 9 декабря 1994 года по делу Stran Greek Refineries and Stratis Andreadis vs. Greece (п.п. 34, 40 постановления от 7 мая 2002 года по делу Бурдов против Российской Федерации) ${ }^{4}$.

По делу Калашников против Российской Федерачии Суд для обоснования своей позиции по вопросу, насколько сроки предварительного и судебного следствий в отношении заявителя соответствовали критерию разумности (п. 1 статьи 6 Конвенции), сослался, в частности,

\footnotetext{
${ }^{4}$ Европейские правовые стандарты в постановлениях Конституционного Суда Российской Федерации. Сборник документов, М.: Юридическая литература, 2003. С. 682-683.
} 
на постановление Суда от 10 декабря 1982 года по делу Corigliano vs. Italy, а также постановление Суда от 24 ноября 1993 года по делу Imbriosca vs. Switzerland (п. 124 постановления от 15 июля 2002 года по делу Калашников против Российской Федерации) ${ }^{5}$.

При рассмотрении дела Посохов против Российской Федерации Суд, констатировав, что требование «законности», закрепленное в параграфе 1 статьи 6 Конвенции, распространяется не только на институциональную основу деятельности суда, но и непосредственно на судей, осуществляющих правосудие, обратился к решению Суда по делу Buscarini vs. San Marino от 4 мая 2000 года (п. 37 постановления от 4 марта 2003 года по делу Посохов против Российской Федерации) ${ }^{6}$.

По делу Смирнова против Российской Федерачии Суд, в частности, указал, что вопрос, являются ли сроки заключения лица под стражей разумными (п. 1 статьи 5 Конвенции), не может быть разрешен абстрактно, без оценки конкретных обстоятельств по делу. Продолжительное заключение под стражей может быть оправданно исключительно в том случае, когда обстоятельства по делу, имеют общественное значение и, несмотря на презумпцию невиновности, обладают приоритетом над правом лица на личную свободу. Такими обстоятельствами могут быть, к примеру, реальная угроза обвиняемого, подсудимого скрыться от следствия, повлиять на ход следствия, а также угроза фальсификации доказательств, тайного сговора со свидетелями и т.д. При этом Суд для обоснования данной позиции по делу сослался на постановление от 26 июня 1991 года по делу Letellier vs. France, постановление от 26 января 1993 года по делу W. vs. Switzerland и др. (п.п. 5762 постановления от 24 июля 2003 года по делу Смирнова против Российской Федерачии) ${ }^{7}$.

В постановлении от 24 июля 2003 года по делу Рябых против Российской Федерации Европейский суд по правам человека подчеркнул, что параграф 1 статьи 6 гарантирует каждому лицу, если речь идет о гражданских правах и обязанностях, право на рассмотрение его дела судом или трибуналом. Причем право на доступ к правосудию, заключающееся в возможности возбудить судебную процедуру по гражданскому делу, является одним из элементов права на суд. Право на суд

\footnotetext{
s Российская газета. 2002, 19 октября.

${ }^{6}$ Российская газета. 2003, 8 июля.

' При изучении данного постановления Суда автор использовал официальный сайт Европейского суда по правам человека - www.echr.coe
} 
являлось бы иллюзорным, если бы правовая система государства - участника Конвенции позволяла не исполнять окончательное решение по делу в интересах одной из сторон. Было бы непостижимо, если параграф 1 статьи 6, предусматривая критерии судебной процедуры: справедливость, публичность, законность, осуществление правосудия в разумные сроки не гарантировал исполнение окончательного судебного решения. Толкование параграфа 1 статьи 6 таким образом, что данная статья касается только доступа к правосудию, осуцествляемому с учетом вышеупомянутых критериев, привело бы к ситуации, несовместимой с принципом верховенства права, который государства обязались соблюдать, ратифицируя Конвенцию. Для подтверждения данной позиции Европейский суд по правам человека сослался на постановление от 19 марта 1997 года по делу Hornsby vs. Greece. Более того, указанная правовая позиция была использована Судом вновь при рассмотрении по существу дела Tимофеев против Российской Федерачии, когда Российская Федерация не исполняла на протяжении почти трех лет судебное решение о выплате компенсации за имущество, незаконно конфискованное вследствие осуждения заявителя (п. 40 постановления от 23 октября 2003 года) ${ }^{8}$.

Нельзя не обратить внимания на тот факт, что в постановлении по делу Рябых против Российской Федерачии Европейский суд по правам человека впервые в своей практике сформулировал правовую позицию, согласно которой право лица на суд является иллюзорным, если правовая система государства предоставляет возможность вышестоящему суду отменить окончательное и обязательное решение по делу на основании заявления государственного чиновника (п.п. 55-56 постановления от 24 июля 2003 года по делу Рябых против Российской Федерачии $)^{9}$. Указанное обстоятельство необходимо принять во внимание, так как Европейский суд по правам человека фактически дал негативную оценку надзорному порядку по гражданским делам, который, как известно, продолжает существовать в гражданском и арбитражном процессах России (глава 41 Гражданского процессуального кодекса Российской Федерации, глава 36 Арбитражного процессуального кодекса Российской Федерации).

По делу Ракевич против Российской Федерации, касающемуся лишения свободы душевнобольного лица, Европейский суд по правам

\footnotetext{
${ }^{8}$ При изучении данного постановления Суда автор использовал официальный сайт Европейского суда по правам человека - www.echr.coe

${ }^{9} \mathrm{CM}$. там же.
} 
человека в постановлении от 28 октября 2003 года подчеркнул, что «понятие «душевнобольное лицо» не может содержать четкие и определенные критерии, поскольку психиатрия постоянно эволюционирует как в медицинском, так и в социальном отношенин. Однако недопустимо лишать лицо свободы исключительно только на том основании, что его либо ее взгляды расходятся с обшепринятыми в обшестве правилами». «Для того чтобы лишение душевнобольного лица являлось законным, с точки зрения статьи 5 параграфа 1 (е) Конвенции, должны быть соблюдены три основных критерия. Во-первых, за исключением экстренных случаев, состояние заинтересованного лица должно быть исследовано объективной медицинской комиссией на предмет сушествования реальной душевной болезни. Во-вторых, болезнь должна сопровождаться такими симптомами, которые оправдывали бы лишение лица свободы. В-третьих, душевная болезнь должна быть на протяжении всего периода лишения лица свободы» (п.п. 26-27 постановления от 28 октября 2003 года) ${ }^{10}$. Для аргументации соответствующих позиций Суд сослался на ранее рассмотренное им дело Winterwerp v. the Netherlands (постановление от 24 октября 1979 года).

Анализируя вопрос законности лишения свободы лица, в том числе душевнобольного, Суд отметил, что «принцип правовой определенности лежит в основе Конвенции. Для того чтобы государство соблюдало этот принцип, нормативно-правовой акт должен быть достаточно четким, чтобы заинтересованное лицо было в состоянии соизмерять свои действия с требованием законодательства, однако принцип не требует, чтобы нормативно-правовой акт был абсолютно точным» (п. 31 постановления) ${ }^{1}$. Здесь Суд сослался на другое ранее принятое им постановление от 26 апреля 1979 года по делу The Sunday Times vs. the United Kingdom.

В постановлении от 29 января 2004 года по делу Кормачева против Российской Федерации, касающемуся неоправданной задержки в рассмотрении трудового дела, Европейский суд по правам человека отметил, что именно на государстве лежит ответственность за организацию своей правовой системы таким образом, чтобы суды могли гарантировать каждому лицу принятие окончательного решения в течение разумных сроков, когда речь идет о гражданских правах и обязаннос-

${ }^{10}$ При изучении данного постановления Суда автор использовал официальный сайт Европейского суда по правам человека - www.echr.coe

"См. там же. 
тях. Государству предоставляются широкие возможности в отношении того, каким образом создать такую систему. Если государство позволяет судебному разбирательству продолжаться сверх разумных сроков, гарантируемых п. 1 статьи 6 Конвенции, не предпринимая какихлибо действий для исправления ситуации, то государство должно быть ответственно за такое упушение (п. 54 постановления от 29 января 2004 года) ${ }^{12}$. Для подтверждения данной позиции по делу Суд сослался на постановление от 29 июля 2003 года по делу Price and Lowe vs. the United Kingdom.

В связи с тем обстоятельством, что при вынесении решения или постановления по делу Европейский суд по правам человека для подтверждения, обоснования своей позиции по делу ссылается на ранее принятые им решения и постановления, возникает справедливый вопрос: возможно ли в данном случае говорить о прецедентном праве Суда.

Известно, что родиной судебного прецедентного права является Великобритания. Под судебным прецедентом, в частности, понимаются решения высших судов, имеюшие обязательную силу для них самих и для нижестоящих судов ${ }^{13}$.

Применительно к правовой системе Великобритании С.К Загайнова подчеркивает, что «судебный прецедент как источник права обладает следуюшими признаками: 1) выносится при разрешении конкретного дела; 2) содержит в себе правовую норму, вследствие чего нижестоящие суды ссылаются на него в своих последующих решениях; 3) обязателен для применения всеми судебными инстанциями...» ${ }^{14}$.

Профессор А.Б. Венгеров указывал, что «в некоторых правовых системах существует механизм, который может превращать некоторые решения судебных органов высокого уровня в судебный прецедент, то есть в соответствующую норму права, которой надо следовать так же, как и закону. Возникает прецедентное право, наряду с правом статутным» ${ }^{15}$.

Таким образом, одним из необходимых признаков, свойств судебного прецедента как источника права является то, что такой прецедент должен содержать правовую норму, то есть общеобязательное правило поведения, обеспечиваемое принудительной силой государства (если

${ }^{12}$ При изучении данного постановления Суда автор использовал официальный сайт Европейского суда по правам человека - www.echr.coe

${ }^{13}$ Правовые системы стран мира. М.: Норма, 2000. С. 107.

${ }^{14}$ С.К. Загайнова. Судебный прецедент: проблемы правоприменения. М.: Норма, 2002. C. 54 .

${ }^{15}$ А.Б. Венгеров. Теория государства и права. М.: Новый Юрист, 1998. С. 418. 
речь идет о национальных правовых нормах). Можно ли утверждать, что решения и/или постановления Европейского суда по правам человека содержат правовую норму? На этот вопрос необходимо дать отрицательный ответ.

Европейский суд по правам человека не создает правовые нормы, а применяет нормы, содержашиеся в Европейской конвенции о зашите прав человека и основных свобод, а также Протоколах к ней. Суд занимается не правотворческой, а правоприменительной деятельностью. Более того, Конвенция непосредственно наделяет Суд полномочием именно применять конвенционные положения, а не создавать новые нормы права. В силу ст. 32 Конвенции «в ведении Суда находятся все вопросы, касающиеся толкования и применения положений Конвенции и Протоколов к ней».

Правотворческая деятельность Суда противоречила бы не только Конвенции, являющейся уставным документом Европейского суда по правам человека, но и общепризнанному принципу международного права - принципу суверенного равенства государств, который, в частности, включает право каждого государства пользоваться правами, присущими полному суверенитету. Последнее означает, что в своих взаимных отношениях государства должны уважать различия в историческом и социально-политическом развитии, разнообразие позиций и взглядов, внутренние законы и административные правила, право определять и осушествлять по своему усмотрению и согласно международному праву отношения с другими государствами ${ }^{16}$. Нормы международного права формируются прежде всего в процессе взаимоотношений между государствами. Норма международного права может обязывать государство только в том случае, если последнее выразит свое согласие в отношении данной правовой нормы. Как справедливо отмечал профессор Г.И. Тункин, «в международных отношениях нет органа, подобно законодательному органу государства, который издавал бы обязательные для государств как основных субъектов международного права правовые нормы. Одной из важных особенностей международного права является то, что его нормы создаются самими субъектами этой системы права» ${ }^{17}$.

Если даже предположить, что Европейский суд по правам человека создает правовые нормы, то последние не являются обязательными для

${ }^{16}$ Международное право / Под ред. проф. В.И. Кузнецова. М.: Юрист, 2001. С. 125-126.

${ }^{17}$ Г.И. Тункин Теория международного права М.: Зерцало, 2000. С. 75. 
государств - участников Конвенции. Государства, ратифицируя Конвенцию и Протоколы к ней, четко выразили свое согласие на обязательность только тех положений, которые содержатся в данных международноправовых актах. Судьи Европейского суда по правам человека не вправе создавать нормы права, которые обязывали бы государства.

Необходимо отметить, что в своих решениях и постановлениях Европейский суд по правам человека, ссылаясь на ранее принятые им судебные акты, использует словосочетание «the case-law» (см., к примеру, параграфы 34, 37 постановления от 25 ноября 1997 года по делу Grigoriades vs. Greece). Словосочетание «the case-law» переводится как прецедентное право ${ }^{18}$. Однако, как свидетельствует практика, Суд в своих решениях и постановлениях использует также и понятие «jurisprudence» (см., к примеру, параграф 270 постановления Суда от 23 апреля 2003 года по делу Aktas vs. Turkey), которое переводится, в частности, как «судебная практика» ${ }^{19}$. Можно предположить, что последнее понятие в большей степени соответствует смыслу и значению практики Европейского суда по правам человека.

Таким образом, решения и постановления Европейского суда по правам человека являются результатом правоприменительной, а не правотворческой деятельности Суда, и поэтому данные судебные акты не могут содержать каких-либо правовых норм. Поэтому говорить о существовании прецедентного права Суда необоснованно. Суд при рассмотрении дела вправе только констатировать, было ли допущено со стороны государства нарушение Конвенции или Протоколов к ней, и в случае констатации такого нарушения присудить заявителю справедливую компенсацию.

Представляется, что применительно к деятельности Суда возможно говорить о создании Судом не правовых прецедентов, содержащих нормы права, а прецедентов толкования. Как было отмечено выше, Суд наделен Конвенцией возможностью не только применять соответствующие международные договоры, но и толковать правовые нормы, содержащиеся в этих документах. Профессор А.Б. Венгеров подчеркивал: «В теории права, кроме судебного прецедента, выделяются и прецеденты толкования правовых норм. Этот результат возникает в процессе толкования правовых норм судебными органами. Прецедент толкования

\footnotetext{
${ }^{18}$ Большой англо-русский словарь / Под. ред. академика Ю.Д. Апресяна и д. фил. наук, проф. Э.М. Медниковой. М.: Русский язык, 1997. Т. 1. С. 328.

${ }^{19}$ См. там же. Т. 2, С. 290.
} 
несколько отличается от судебного прецедента своей ориентацией на логические проблемы содержания того или иного закона» ${ }^{20}$.

Применение международных договоров неразрывно связано с их толкованием. Под толкованием норм международного права понимается выяснение содержания нормы, ее целей с учетом результатов ее применения в конкретной ситуации ${ }^{21}$. Как справедливо отмечал венгерский профессор Д. Харасти, «толкование имеет своей целью разъяснение смысла текста договора, тогда как применение предполагает установление последствий, вытекающих для сторон» ${ }^{2}$. Перед тем как применить то или иное положение, содержащееся в тексте Конвенции, Европейский суд по правам человека должен истолковать соответствуюшую норму международного права, уяснить, в частности, ее смысл, дух, нормативное содержание. Конвенция содержит понятия, объем которых можно определить только посредством толкования, осушествляемого Европейским судом по правам человека. К примеру, что понимается под пытками, бесчеловечным или унижающим достоинство обрашением по статье 3 Конвенции, что понимается под гражданскими правами и обязанностями и уголовным обвинением в свете статьи 6 Конвенции, а также под частной жизнью согласно статье 8 Конвенции, что включается в понятие собственности, защищаемой статьей 1 Протокола № 1 к Конвенции.

В результате толкования Судом конвенционных положений складываются правовые позиции, которые помогают Суду в дальнейшем более зффективно и оперативно рассматривать дела. Как справедливо подчеркивает проф. В.А. Туманов, за правовыми позициями «скрываются сложившиеся в правоприменительной практике установки, из которых исходят при рассмотрении конкретных дел; подтвержденные многократным применением толкования правовых понятий и норм, критерии, выработанные практикой для рассмотрения определенных категорий дел» ${ }^{23}$.

Статья 3 Конвенции, запрещающая, в частности, подвергать коголибо бесчеловечному или унижающему человеческое достоинство

${ }^{20}$ А.Б. Венгеров. Указ. соч., С. 421.

${ }^{21}$ И.И. Лукашук, О. И. Лукашук. Толкование норм международного права: Учебное пособие для вузов. М., 2002. С. 14.

${ }^{22}$ Цит. по: А.Н. Талалаев. Венская конвенция о праве международных договоров. Комментарий. М.: Юридическая литература, 1997. С. 80.

${ }^{23}$ В.А. Туманов. Европейский суд по правам человека. Очерк организации и деятельности. М.: Норма, 2001. С. 106-107. 
обращению или наказанию, не раскрывает, что следует понимать под бесчеловечным обращением или наказанием. В ходе рассмотрения ряда дел Европейский суд по правам человека определил, что понятие «бесчеловечное обращение» включает в себя, по крайней мере, такие действия, которыми умышленно причиняются сильные страдания, нравственные или физические, что в данной ситуации является неприемлемым ${ }^{24}$.

Представляется, что правовые позиции, возникающие вследствие применения Судом Конвенции и Протоколов к ней, можно подразделить на две категории - материальные и процессуальные (процедурные) правовые позиции. Если Европейский суд по правам человека в ходе толкования раскрывает нормативное содержание конвенционных положений, то в этом случае речь идет о материальных правовых позициях. К примеру, в ходе неоднократного применения статьи 6 Суд применительно к понятию «гражданских прав и обязанностей» выработал правовую позицию, согласно которой указанное понятие носит автономный характер. Законодательство, на основании которого решается вопрос о правах и обязанностях (гражданское, коммерческое, административное и т.д.), и орган, на который возложены полномочия по разрешению спора, не имеют большого значения (параграф 94 постановления от 16 июля 1971 года по делу Рингейзен протие. Австрии). Ключевым моментом в определении того, применима или нет статья 6, является то, имеет ли результат судебного разбирательства определяющее значение для частных прав и обязанностей (параграф 47 постановления от 24 октября 1989 года по делу $X$. против Франции) ${ }^{25}$.

Осушествляя толкование понятия «частная жизнь», предусмотренного в статье 8 Конвенции, Суд, в частности, исходит из следующей правовой позиции: было бы непозволительно ограничить понятие частной жизни внутренним кругом, в котором может жить отдельный человек своей личной жизнью, которую он выбирает, и исключить оттуда целиком внешний мир, не входящий в этот круг. Уважение к личной жизни должно также включать определенный набор прав для установления и развития взаимоотношений с дру-

\footnotetext{
${ }^{24}$ Европейская конвенция о защите прав человека и основных свобод. Статья 3. Запрещение пыток. М.: Российская академия правосудия. 2002. С. 16.

${ }^{25}$ При изучении данных постановлений Суда автор использовал официальный сайт Европейского суда по правам человека.
} 
гими аспектами жизни человека (постановление от 16 декабря 1992 года по делу Niemietz vs. Germany) ${ }^{26}$.

Однако, если в ходе неоднократного применения конвенционных положений у Суда вырабатывается алгоритм (процедура) применения соответствующей статьи, то в этом случае речь идет о процессуальной правовой позиции. К примеру, применяя статью 10 Конвенции (свобода выражения мнения), Европейский суд по правам человека в первую очередь изучает, было ли осушествлено вмешательство в право, гарантируемое Конвенцией. Затем Суд анализирует, насколько вмешательство было законным, то есть соответствовало правовым нормам, действующим в правовой системе соответствующего государства. В-третьих, Суд обращает внимание на то, преследовало ли такое вмешательство законную (общественную) цель, непосредственно предусмотренную в тексте статьи 10. И в-четвертых, Суд определяет, насколько необходимо было вмешательство с учетом конкретных обстоятельств дела. Данный алгоритм действий Суда имеет большое практическое значение. Если при ответе на какой-либо вопрос, указанный выше, Судом дается отрицательный ответ, то констатируется факт нарушения государством прав, закрепленных в данном случае в статье 10 Конвенции.

Таким образом, вследствие толкования Европейским судом по правам человека Конвенции и Протоколов к ней образуются правовые позиции (прецеденты толкования), формой существования которых являются решения и постановления Суда. Указанные правовые позиции не содержат каких-либо правовых норм, и поэтому, как уже было подчеркнуто выше, отсутствуют какие-либо основания для существования прецедентного права, создаваемого Европейским судом по правам человека.

В связи с созданием Судом правовых позиций возникает справедливый вопрос о месте решений и постановлений, принимаемых Европейским судом по правам человека, в правовой системе России.

Как было отмечено выше, право формировать, определять национальную правовую систему принадлежит исключительно государству. Иные государства и международные организации обязаны уважать это суверенное право. Только государство вправе определять, какие элементы, составные части формируют его национальную правовую сис-

${ }^{26}$ При изучении данного постановления Суда автор использовал официальный сайт Европейского суда по правам человека. 
тему. К примеру, в п. 4 статьи 15 Конституции Российской Федерации четко определено, что общепризнанные принципы и нормы международного права и международные договоры РФ являются составной частью ее правовой системы. Решения и постановления Европейского суда по правам человека не являются международным договором РФ и тем более не содержат общепризнанных принципов и норм международного права. Однако объем правовой системы России определяется не только Конституцией, но и иными источниками национального права России. Поэтому необходимо обратить внимание на статью 1 Федерального закона РФ «О ратификации Конвенции о защите прав человека и основных свобод и Протоколов к ней» от 30 марта 1998 года, согласно которой «Российская Федерация в соответствии со статьей 46 Конвенции признает ipso facto и без специального соглашения юрисдикцию Европейского суда по правам человека обязательной по вопросам толкования и применения Конвенции и Протоколов к ней в случаях предполагаемого нарушения Российской Федерацией положений этих договорных актов, когда предполагаемое нарушение имело место после их вступления в действие в отношении Российской Федерации» ${ }^{27}$.

Закон признает обязательной для России юрисдикцию Суда по вопросам толкования и применения Конвенции и Протоколов к ней. Как было отмечено выше, толкуя и применяя конвенционные положения при рассмотрении дел, Суд принимает решения и постановления.

Как следует из содержания вышеупомянутого закона, последний имплементировал (включил) в правовую систему не любые судебные акты, принятые Европейским судом по правам человека, а только такие, которые отвечают определенным критериям.

Во-первых, судебный акт должен быть принят в отношении Российской Федерации, то есть ответчиком по делу должна являться Российская Федерация. Если по рассматриваемому делу Российская Федерация выступает в качестве третьего лица (статья 36), то судебный акт, принятый в данном случае, не станет частью правовой системы России.

Во-вторых, судебный акт должен устанавливать факт нарушения Конвенции и/или Протоколов Российской Федерации. Данный критерий имеет важное значение. Как было подчеркнуто выше, Европейский суд по правам человека, рассматривая дело, принимает два вида судебных актов - решение о приемлемости и постановление. Конста-

${ }^{27}$ Собрание законодательства Российской Федерации № 14 от 6 апреля 1998 года, cr. 1514 . 
тация Судом факта нарушения государством-участником Конвенции закрепляется исключительно в постановлениях, поэтому решения о приемлемости, принятые Судом даже в отношении России, согласно закону не являются обязательными для России и, следовательно, не являются частью ее правовой системы. Более того, не каждое постановление Суда, принятое по делу, где в качестве ответчика выступает Российская Федерация, является частью правовой системы, а только такое, в котором Судом констатирован факт нарушения Россией конвенционных положений.

В-третьих, постановление Европейского суда, вынесенное против Российской Федерации, где констатирован факт нарушения Россией Конвенции и/или Протоколов к ней, должно вступить в законную силу. Данный критерий не предусматривается в законе, однако данное положение непосредственно следует из содержания Конвенции, согласно статье 44 которой постановление любой из Палат становится окончательным, если: а) стороны не заявляют, что они будут просить о передаче дела в Большую Палату; или б) по истечении трех месяцев с даты вынесения постановления не поступило обращения о передаче дела в Большую Палату; или с) Коллегия Большой Палаты отклоняет обрашение о передаче дела в Большую Палату.

Таким образом, с учетом вышеуказанных критериев из восьми постановлений, вынесенных на сегодняшний день Европейским судом по правам человека, частью правовой системы России стали только семь постановлений - постановление от 7 мая 2002 года по делу Бурдов против Российской Федерачии, постановление от 15 июля 2002 года по делу Калашников против Российской Федерачии, постановление от 4 марта 2003 года по делу Посохов против Российской Федерачии, постановление от 24 июля 2003 года по делу Смирнова против Российской Федерауии, постановление от 24 июля 2003 года по делу Рябых против Российской Федерачии, постановление от 23 октября 2003 года по делу Тимофеев против Российской Федерации, постановление от 28 октября 2003 года по делу Ракевич против Российской Федерации. Постановление от 29 января 2004 года по делу Кормачева против Российской Федерации с учетом всех обстоятельств станет частью правовой системы России 29 апреля 2004 года.

Постановления Европейского суда по правам человека, одновременно отвечающие вышеупомянутым критериям, являются обязательными для Российской Федерации. Причем данная обязательность имеет 
как международное, так и национально-правовое значение. Международно-правовой аспект обязательности постановлений Европейского суда по правам человека закреплен в статье 46 Конвенции, согласно которой «1. Высокие Договаривающиеся Стороны обязуются исполнять окончательные постановления Суда по делам, где они являются сторонами. 2. Окончательное постановление Суда направляется Комитету Министров, который осушествляет надзор за его исполнением». Как известно, за всю история Европейского суда по права человека не было ни одного неисполненного окончательного постановления.

Национально-правовой аспект обязательности постановлений Суда закрепляется в источниках права государств - участников Конвенции и Протоколов к ней. Применительно к Российской Федерации основным документом является уже вышеупомянутый Закон о ратификации Конвенции. Как следует из содержания закона, постановления Европейского суда по правам человека, содержашие нарушения Россией Конвенции и/или Протоколов, обязательны в рамках правовой системы России по вопросам толкования и применения соответствующих международно-правовых актов. Вопросы толкования охватывают те правовые позиции (прецеденты толкования), которые излагаются Судом в соответствуюшем постановлении. Вопросы применения Конвенции охватывают, в частности, вопросы исполнения постановлений, выносимых Судом против Российской Федерации.

Таким образом, государственные и муниципальные органы Российской Федерации должны не только исполнять постановление Суда, если на них возложена такая обязанность национальным законодательством, но и в своей деятельности руководствоваться Конвенцией с учетом правовых позиций, изложенных Судом в постановлениях против Российской Федерации.

Рассматривая национально-правовой аспект обязательности окончательных постановлений Суда, нельзя не обратить внимания на содержание статьи 413 Уголовно-процессуального кодекса РФ (далее УПК РФ), а также статьи 311 Арбитражного процессуального кодекса РФ (далее - АПК РФ). В силу п.П. 2 п. 4 статьи 413 УПК РФ основанием возобновления производства по уголовному делу является установленное Европейским судом по правам человека нарушение положений Конвенции о защите прав человека и основных свобод при рассмотрении судом Российской Федерации уголовного дела, связанного с: a) применением федерального закона, не соответствующего положе- 
ниям Конвенции о защите прав человека и основных свобод; б) иными нарушениями положений Конвенции о защите прав человека и основных свобод» ${ }^{28}$.

Согласно п. 7 статьи 311 АПК РФ «установленное Европейским судом по правам человека нарушение положений Конвенции о защите прав человека и основных свобод при рассмотрении арбитражным судом конкретного дела, в связи с принятием решения по которому заявитель обращался в Европейский суд по правам человека», также является основанием для пересмотра судебных актов по вновь открывшимся обстоятельствам ${ }^{29}$.

Таким образом, постановления Европейского суда по правам человека, вынесенные против Российской Федерации и устанавливающие нарушение Россией Конвенции и/или Протоколов к ней, являются основанием для пересмотра решения по вновь открывшимся обстоятельствам. Необходимо отметить, что Конвенция в этом случае не предусматривает обязанности государств пересматривать дела, рассмотренные в пределах их юрисдикции. Представляется, что указанные выше процессуальные положения являются свидетельством уважения Россией Конвенции и Протоколов к ней.

Постановления Европейского суда по правам человека, содержащие факт нарушения Конвенции и/или Протоколов к ней, вынесенные против России и вступившие в законную силу, стали частью правовой системы Российской Федерации и, таким образом, стали обязательными в вопросах толкования и применения Конвенции и Протоколов к ней. Однако это обстоятельство не свидетельствует о том, что можно говорить о данных постановлениях как об источниках прецедентного права России. Постановления Европейского суда по правам человека, как подчеркивалось выше, не содержат каких-либо правовых норм, обязательных как для государства в целом, так и для субъектов национального права. Правовые позиции, содержащиеся в указанньх постановлениях Суда, являются следствием толкования Судом Конвенции и Протоколов к ней, то есть следствием правоприменительной, а не правотворческой деятельности Суда.

${ }^{28}$ Собрание законодательства Российской Федерации № 22. 2002. Ст. 2027.

${ }^{29}$ Комментарий к Арбитражному процессуальному кодексу Российской Федерации. М.: Российская академия правосудия, 2003. С. 786-787. Необходимо подчеркнуть, что указанных процессуальных положений не содержит Гражданский процессуальный кодекс Российской Федерацией. Представляется, что в этом случае суд общей юрисдикции, рассматривающий гражданское дело, мог бы руководствоваться аналогией закона как средством восполнения пробелов. 
Известно, что правовые позиции Суда находят свое закрепление в решениях о приемлемости, постановлениях, принимаемых в отношении других государств - участников Конвенции. Однако, как было отмечено выше, данные судебные акты не формируют правовую систему России и поэтому не являются обязательными для России. Однако государственные и муниципальные органы Российской Федерации в своей деятельности могли бы руководствоваться такими решениями и постановлениями и закрепляемыми в них правовыми позициями, принимая во внимание их прецедентный характер, а также руководствуясь общепризнанным принципом международного права - принципом добросовестного выполнения международных обязательств. 